ing. Possibly more patients would have shown an abnormality had vertical nystagmus also been recorded.

Similar phenomena were seen in the patients with suspected multiple sclerosis. In these patients no definite diagnosis could be made as there was no evidence of more than one discrete neurological lesion. Some of these patients were found to have nystagmus on routine examination and so clearly had evidence of brain-stem dysfunction. These all showed an increase in nystagmus on body heating. Although this is not evidence of a further neurological lesion, we think that it is highly suggestive that the lesion is one of demyelination. In those in whom there was no initial nystagmus three out of seven developed it on heating. We believe that the appearance of central nystagmus produced by raising body temperature is evidence of previously unrecognised lesions affecting the vestibular and oculomotor connections within the brain stem.

Apart from multiple sclerosis many other diseases affecting the central nervous system also result in myelin breakdown. Not surprisingly, therefore, various physical signs, including weakness, reflex changes, and impairment of visual acuity, have been reported when patients with other neurological diseases are heated. Using the hot-bath test, Nelson et al ${ }^{11}$ described the appearance and increase of nystagmus in 33 out of 84 patients studied. Their positive results were obtained in nine patients with multiple sclerosis; 12 with epilepsy, most of whom were receiving anticonvulsants; 10 with "diffuse diseases of the central nervous system"; one with labyrinthitis; and, surprisingly, one with compression of the cauda equina. They also noted that in multiple sclerosis these changes occurred earlier and with smaller increases in body temperature. As yet we have had no positive results in patients with diseases other than multiple sclerosis, even though most of them had nystagmus.

From our encouraging initial results in patients with proved and suspected multiple sclerosis we think that recording nystagmus before and after raising the body temperature will prove to be a practicable diagnostic procedure. In cases of spastic paraparesis abnormal visual evoked responses are important as they indicate abnormalities outside the pyramidal pathways. The appearance of nystagmus on body heating in such cases, however, may not necessarily be due to a further discrete neurological lesion. This technique, therefore, may prove to be most valuable in such cases when a definite level below the brain stem can be identified. The investigation may also be important if the clinical history and physical examination do not suggest an abnormality within the brain stem-for example, acute retrobulbar neuritis.

The equipment needed to record visual evoked responses is not yet available in all neurological centres. On the other hand, the equipment necessary for recording nystagmus and that for heating the patient-namely, an electroencephalograph and a neurological heat cradle-are in current use. The technique is simple, causes little discomfort to the patient, and may be performed in the electroencephalography department, in the ward, or in the outpatient clinic. Our results suggest that it will provide useful additional information in patients suspected of having multiple sclerosis.

We thank Dr C J Earl and Dr M J G Harrison for allowing us to study their patients and for advice on preparing this paper; and Mr J Leech, of the MRC Hearing and Balance Unit, National Hospital, for technical advice.

Requests for reprints should be addressed to: Dr John Jestico, National Hospital for Nervous Diseases, Queen Square, London WC1N 3BG.

\section{References}

${ }^{1}$ Simons, D J, Bulletin of the Neurological Institute of New York, 1937, 6, 385. ${ }^{2}$ Guthrie, T C, Archives of Neurology and Psychiatry, 1951, 65, 437.

${ }^{3}$ Edmund, J, and Fog, T, Archives of Neurology and Psychiatry, 1955, 73, 316.

${ }^{4}$ Nelson, D A, and McDowell, F, fournal of Neurology, Neurosurgery, and Psychiatry, 1959, 22, 113.

${ }_{5}$ McAlpine, D, Lumsden, C E, and Acheson, E D, Multiple Sclerosis: a reappraisal, 2nd edn, p 202. Edinburgh, Churchill Livingstone, 1972.

${ }^{6}$ Halliday, A M, McDonald, W I, and Mushin, J, British Medical fournal, 1973, 4, 661 .

${ }^{7}$ Robinson, K, and Rudge, P, Lancet, 1975, 1, 1164.

${ }^{8}$ Carter, S, Sciarra, D, and Merritt, H H, Association for Research in Nervous and Mental Disease Proceedings, 1950, 28, 471.

9 Rasminsky, M, Archives of Neurology, 1973, 28, 287.

${ }^{10}$ Davis, F A, et al, fournal of Neurology, Neurosurgery, and Psychiatry, $1976,39,442$.

${ }_{11}$ Nelson, D A, Jeffreys, W H, and McDowell, F, Archives of Neurology and Psychiatry, 1958, 79, 31.

\title{
Can phenformin-induced lactic acidosis be prevented?
}

\author{
E A M GALE, R B TATTERSALL
}

and should not have been given phenformin. Four had hypertension and minimal evidence of renal disease, while in two no predisposing factor was identified. There are so many contraindications to the use of phenformin that it is doubtful whether patients on the drug can be monitored adequately. We suggest that phenformin should be withdrawn from general use.

Although patients taking phenformin are more likely to vascular, or hepatic disease, criteria for safe use of the drug are not well established. Eight diabetics died of lactic acidosis in Nottingham in 1972-5 and all were taking phenformin in therapeutic doses. Six had attended the diabetic clinic within a month of their terminal illness. Two patients had appreciable renal impairment

General Hospital, Nottingham NG1 6HA

E A M GALE, MRCP, registrar

R B TATTERSALL, MD, MRCP, consultant physician

\section{Introduction}

Soon after its introduction in 1957 phenformin was found to increase blood lactate concentrations. ${ }^{1}$ Nevertheless, the clinical syndrome of lactic acidosis seemed to be a rare complication, found only when other causes of lactate overproduction, such as shock, were present. In a comprehensive review in 1970 Oliva $^{2}$ could find only 18 published cases of phenforminassociated lactic acidosis. But the true incidence of this complication seems to have been seriously underestimated: in the last year over 50 cases have been reported from four centres. ${ }^{3-6}$ 
Overdoses of phenformin in otherwise healthy people sometimes ${ }^{78}$ cause lactic acidosis, but it is generally thought that in the absence of predisposing factors lactic acidosis is not an appreciable risk in patients taking therapeutic doses. The most important predisposing factors are renal impairment, which reduces the excretion of phenformin, and liver disease, which results in impaired lactate metabolism. Heart failure may produce both these effects simultaneously. Any condition that causes hypoxia, such as acute myocardial infarction or respiratory disease, can also precipitate lactic acidosis in patients on phenformin.

Phenformin is still widely used in the United Kingdom. In 1975 enough capsules were dispensed to treat 30000 patients. But can all these patients be adequately protected from the risk of lactic acidosis ? On the assumption that lactic acidosis rarely occurs spontaneously in patients on phenformin, it has been suggested that the condition could be prevented if patients were screened for renal, hepatic, and cardiovascular disease before and during treatment. ${ }^{910}$ Although this advice is sound in theory, it is likely to prove difficult to put into practice since diabetics are especially predisposed to renal and cardiovascular disease. Furthermore, the terms "renal disease" and "cardiovascular disease" are vague and raise many questions; for example, How intensively does renal function need to be investigated before starting a patient on phenformin? Does mild hypertension, which is common in elderly diabetics, count as cardiovascular disease? We analysed the histories of eight patients who died of phenformin-induced lactic acidosis to see if their deaths could be attributed to inadequate screening.

\section{Methods}

There are no generally accepted diagnostic criteria for lactic acidosis. We considered it present when the blood lactate concentration was over $7 \mathrm{mmol} / \mathrm{l}(63 \mathrm{mg} / 100 \mathrm{ml})$ or, when lactate could not be measured, when the anion gap was greater than $30 \mathrm{mmol} / \mathrm{l}$ with a negative Acetest reaction on undiluted plasma. In the two patients in whom blood lactate was not measured we cannot exclude the possibility that raised levels of 3-hydroxybutyrate, which is not measured by the Acetest method, contributed to the acidosis. Blood lactate was estimated by the Boehringer enzymatic method.

\section{Results}

In a retrospective survey of diabetics admitted to medical wards in Nottingham General Hospital in 1972-5 we found eight patients (three men and five women) who satisfied our criteria for lactic acidosis. All were taking phenformin and all died. In the same period 69 patients over the age of 50 were admitted with diabetic ketoacidosis or hyperosmolar coma, and 27 died.

All eight patients had attended the diabetic clinic and six were being seen regularly; these six had attended the clinic within three weeks of their death. The presenting and metabolic features of their illnesses were remarkably similar (table I). All patients had a prodromal illness with vomiting and malaise lasting one to seven days. Four had consulted their general practitioner and a barium meal had been ordered at the diabetic clinic for a fifth. Two patients complained of abdominal pain and three of diarrhoea. Drowsiness and acidotic breathing developed in the $\mathbf{4 8}$ hours before admission, by which time six patients were in coma. All were shocked, and the systolic blood pressure was under $90 \mathrm{~mm} \mathrm{Hg}$ in seven. Two patients were hypothermic (rectal temperature below $33^{\circ} \mathrm{C}$ ), and in one this led to initial diagnostic confusion.

Clearly the non-specific early symptoms delayed referral to hospital, and in no case was the correct diagnosis considered before admission. Nevertheless, lactic acidosis was suspected and appropriate treatment started in all cases within two hours of admission to hospital. All patients received large infusions of bicarbonate, and five were also treated with insulin. Seven died before the acidosis was corrected (mean survival time six and a half hours), while the eighth required artificial ventilation and died five days later.

Previous health-These patients seemed to form a representative cross section of middle-aged and elderly diabetics (table II). Their mean age was 63 years and diabetes had lasted from five days to 14 years. Six were leading normal lives, one had an old hemiplegia, and the other was confined to a wheelchair by Parkinson's disease. Four patients were more than $20 \%$ above their ideal body weight. Before starting treatment with phenformin five patients had hypertension, although in three (cases 1-3) the blood pressure was satisfactorily controlled with methyldopa. Another patient became hypertensive after five years on phenformin. Diabetic complications were uncommon: two patients had background retinopathy and three proteinuria.

Drug treatment-All eight patients were taking phenformin (table III). In two the dose had been increased to $200 /$ mg day together with a sulphonylurea in an attempt to avoid insulin. Lactic acidosis developed rapidly on this higher dose, after five days in one patient and after 15 in the other. Another patient who had impaired renal function (case 2), developed lactic acidosis after only five days on

TABLE I-Clinical and biochemical features on admission

\begin{tabular}{|c|c|c|c|c|c|c|c|c|}
\hline $\begin{array}{l}\text { Case } \\
\text { No }\end{array}$ & $\begin{array}{l}\text { Age and } \\
\text { sex }\end{array}$ & $\begin{array}{c}\text { Level of } \\
\text { consciousness }\end{array}$ & $\begin{array}{c}\text { Temperature } \\
\left({ }^{\circ} \mathrm{C}\right)\end{array}$ & $\begin{array}{c}\text { Arterial } \\
\text { pH }\end{array}$ & $\begin{array}{c}\text { Blood urea } \\
(\mathrm{mmol} / \mathrm{l})\end{array}$ & 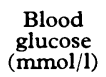 & $\begin{array}{l}\text { Plasma } \\
\text { lactate } \\
(\mathrm{mmol} / \mathrm{l})\end{array}$ & $\begin{array}{c}\text { Acetest } \\
\text { (undiluted } \\
\text { plasma) }\end{array}$ \\
\hline $\begin{array}{l}1 \\
2 \\
3 \\
4 \\
5 \\
6 \\
7 \\
8\end{array}$ & $\begin{array}{ll}48 & M \\
58 & M \\
58 & \mathrm{~F} \\
65 & \mathrm{~F} \\
65 & \mathrm{M} \\
73 & \mathrm{~F} \\
75 & \mathrm{~F} \\
62 & \mathrm{~F}\end{array}$ & $\begin{array}{l}\text { Unconscious } \\
\text { Unconscious } \\
\text { Conscious } \\
\text { Unconscious } \\
\text { Conscious } \\
\text { Unconscious } \\
\text { Unconscious } \\
\text { Unconscious }\end{array}$ & $\begin{array}{l}36 \\
36 \cdot 5 \\
35 \cdot 8 \\
30 \cdot 8 \\
32 \cdot 9 \\
34 \cdot 4 \\
35 \cdot 5 \\
35 \cdot 0\end{array}$ & $\begin{array}{l}6 \cdot 68 \\
6 \cdot 75 \\
6 \cdot 85 \\
6 \cdot 80 \\
6 \cdot 78 \\
6 \cdot 99 \\
6 \cdot 84 \\
6 \cdot 68\end{array}$ & $\begin{array}{l}30 \cdot 5 \\
16 \cdot 4 \\
16 \cdot 0 \\
50 \cdot 0 \\
26 \cdot 7 \\
21 \cdot 0 \\
15 \cdot 8 \\
19 \cdot 0\end{array}$ & $\begin{array}{r}14 \cdot 4 \\
22 \cdot 1 \\
4 \cdot 4 \\
8 \cdot 9 \\
42 \cdot 6 \\
8 \cdot 6 \\
9 \cdot 5 \\
5 \cdot 0\end{array}$ & $\begin{array}{c}12 \cdot 8 \\
* \\
14 \cdot 0 \\
18 \cdot 4 \\
* \\
29 \cdot 0 \\
17 \cdot 0 \\
7 \cdot 2\end{array}$ & $\begin{array}{l}\text { Trace } \\
\text { Negative } \\
\text { Negative } \\
\text { Negative } \\
\text { Negative } \\
\text { Trace } \\
\text { Trace } \\
\text { Negative }\end{array}$ \\
\hline
\end{tabular}

*Not measured (see text).

Conversion: SI to traditional units-Urea: $1 \mathrm{mmol} / 1 \approx 6 \mathrm{mg} / 100 \mathrm{ml}$. Glucose: $1 \mathrm{mmol} / 1 \approx 18 \mathrm{mg} / 100 \mathrm{ml}$. Lactate: $1 \mathrm{mmol} / 1 \approx 9 \mathrm{mg} / 100 \mathrm{ml}$.

TABLE II-General health of patients before they developed lactic acidosis

\begin{tabular}{|c|c|c|c|c|c|c|c|c|c|}
\hline \multirow{2}{*}{$\begin{array}{l}\text { Case } \\
\text { No }\end{array}$} & \multirow{2}{*}{$\begin{array}{l}\text { Duration } \\
\text { of diabetes }\end{array}$} & \multirow{2}{*}{$\begin{array}{l}\text { General } \\
\text { health }\end{array}$} & \multirow{2}{*}{ Obesity* } & \multirow{2}{*}{ Retinopathy } & \multicolumn{2}{|c|}{ Blood pressure (mm Hg) } & \multirow{2}{*}{ Proteinuria } & \multicolumn{2}{|c|}{ Blood urea $(\mathrm{mmol} / \mathrm{l})$} \\
\hline & & & & & $\begin{array}{l}\text { Before starting } \\
\text { phenformin }\end{array}$ & $\begin{array}{c}\text { Most } \\
\text { recently }\end{array}$ & & $\begin{array}{l}\text { Before starting } \\
\text { phenformin }\end{array}$ & $\underset{\text { recently }}{\text { Most }}$ \\
\hline $\begin{array}{l}1 \\
2 \\
3 \\
4 \\
5\end{array}$ & $\begin{array}{l}9 \text { years } \\
5 \text { days } \\
7 \text { years } \\
10 \text { years } \\
14 \text { years }\end{array}$ & $\begin{array}{l}\text { Old hemiplegia } \\
\text { Good } \\
\text { Good } \\
\text { Good } \\
\text { Poorly } \\
\text { controlled }\end{array}$ & $\begin{array}{l}- \\
+ \\
+ \\
+ \\
-\end{array}$ & $\begin{array}{c}- \\
- \\
- \\
\text { Background }\end{array}$ & $\begin{array}{l}160 / 95 \dagger \\
160 / 90^{\dagger} \\
130 / 95 \dagger \\
160 / 90 \\
140 / 70\end{array}$ & $\begin{array}{l}160 / 90 \\
160 / 110 \\
220 / 120 \\
160 / 80\end{array}$ & $\begin{array}{l}\overline{+} \\
\pm \\
+ \\
-\end{array}$ & $\begin{array}{r}3 \cdot 0 \\
11 \cdot 4 \\
6 \cdot 8 \\
5 \cdot 2 \\
7 \cdot 0\end{array}$ & $\begin{array}{r}11 \cdot 4 \\
9 \cdot 3 \\
7 \cdot 6\end{array}$ \\
\hline $\begin{array}{l}6 \\
7 \\
8\end{array}$ & $\begin{array}{l}4 \text { months } \\
4 \text { years } \\
6 \text { months }\end{array}$ & $\begin{array}{l}\text { Parkinsonism } \\
\text { Good } \\
\text { Good }\end{array}$ & $\frac{+}{+}$ & Background & $\begin{array}{l}180 / 90 \\
200 / 100 \\
190 / 110\end{array}$ & $200 / 110$ & $\overline{+}$ & $\begin{array}{l}4 \cdot 5 \\
4 \cdot 0 \\
5 \cdot 8\end{array}$ & $\begin{array}{l}6.6 \\
8.5 \\
4.7\end{array}$ \\
\hline
\end{tabular}

* More than $20 \%$ over ideal body weight (Metropolitan Life Insurance Co 1959).

+ While on methyldopa.
\pm Within three months of lactic acidosis. 
TABLE III-Drug treatment

\begin{tabular}{|c|c|c|c|}
\hline \multirow[b]{2}{*}{$\begin{array}{l}\text { Case } \\
\text { No }\end{array}$} & \multicolumn{2}{|c|}{ Phenformin treatment } & \multirow[b]{2}{*}{ Other drug treatment } \\
\hline & $\begin{array}{c}\text { Daily } \\
\text { dose (mg) }\end{array}$ & $\begin{array}{l}\text { Length of } \\
\text { treatment with } \\
\text { sustained- } \\
\text { release capsules }\end{array}$ & \\
\hline 1 & 100 & & $\begin{array}{l}\text { Methyldopa, hydrochlorothiazide, } \\
\text { amiloride, chlorpropamide }\end{array}$ \\
\hline $\begin{array}{l}2 \\
3 \\
4 \\
5 \\
6 \\
7\end{array}$ & $\begin{array}{l}100 \\
100 \\
100 \\
200 \\
100 \\
200\end{array}$ & $\begin{array}{l}5 \text { days } \\
8 \text { years } \\
5 \text { years } \\
15 \text { days } \\
4 \text { months } \\
5 \text { days }\end{array}$ & $\begin{array}{l}\text { Methyldopa, bendrofluazide } \\
\text { Methyldopa } \\
\text { Frusemide, spironolactone } \\
\text { Digoxin, glibenclamide } \\
\text { Chlorpropamide, benzhexol } \\
\text { Chlorpropamide, salbutamol, }\end{array}$ \\
\hline 8 & 100 & 6 months & Methyldopa \\
\hline
\end{tabular}

phenformin $100 \mathrm{mg} /$ day. Of the other five patients, who were all receiving $100 \mathrm{mg} /$ day, two developed lactic acidosis within six months and three developed it two to eight years after starting phenformin. All patients were also taking other drugs (table III). Four were receiving diuretics, which may impair renal function. In two cases these were adjuncts to other antihypertensive treatment and in a third the diuretic was being taken alone for hypertension. The fourth patient developed lactic acidosis soon after she started taking large doses of diuretics for heart failure. Four patients were receiving methyldopa, which may affect liver function ${ }^{11}$ and might have impaired metabolism of either phenformin or lactate. Nevertheless, there were no histological abnormalities in the liver in the three patients on methyldopa who came to necropsy. Alcohol is known to predispose to lactic acidosis, but there was no evidence that any of the patients had taken any recently or were alcoholics.

Renal function-One patient was started on phenformin despite having abnormal renal function (case 2). The other seven had normal blood urea concentrations when they started taking phenformin. Two patients who were being supervised by their general practitioners had not had a recent blood urea estimation. In the other five the blood urea had been measured within three months of their death and the mean was only marginally increased at $7.3 \mathrm{mmol} / 1(44 \mathrm{mg} / 100 \mathrm{ml})$ (range $4 \cdot 7-9 \cdot 3 \mathrm{mmol} / 1$ or $28-56 \mathrm{mg} / 100 \mathrm{ml}$ ). Two patients, both with background diabetic retinopathy, had shown intermittent albuminuria, although in neither was it persistent. When admitted with lactic acidosis all patients were azotaemic (blood urea $15-50 \mathrm{mmol} / \mathrm{l}$ $(90-300 \mathrm{mg} / 100 \mathrm{ml})$ ).

Necropsy findings-Six of the eight patients underwent necropsy. One (case 2) had shrunken kidneys, weighing 70 and $80 \mathrm{~g}$. In the others there were no significant macroscopic or microscopic abnormalities of kidneys or liver. No patient had postmortem evidence of any associated acute illness that might have precipitated lactic acidosis.

\section{Case reports}

The following case reports illustrate the course in three of the patients.

CASE 2

A 58-year-old man attended the diabetic clinic with a three-week history of thirst and polyuria. He had been treated for hypertension for five years and had a trace of proteinuria but no diabetic retinopathy. Although he was not obese treatment was started with a 150-g carbohydrate diet and phenformin slow-release capsules $50 \mathrm{mg}$ twice daily. Blood was taken for urea and creatinine measurements, and the creatinine concentration was raised at $200 \mu \mathrm{mol} / 1(2.3 \mathrm{mg} / 100 \mathrm{ml})$. No action was taken in the five days that elapsed before he was admitted in coma due to lactic acidosis. Necropsy showed scarred kidneys weighing 70 and $80 \mathrm{~g}$.

Comment-The coexistence of hypertension and proteinuria might have suggested renal disease, and phenformin should not have been started until his renal function had been assessed.

\section{CASE 4}

A previously fit 65 -year-old woman had a 10-year history of diabetes and had been taking phenformin slow-release capsules $50 \mathrm{mg}$ twice daily for the past five years. Although her blood pressure had been normal when she started phenformin, it had gradually risen over the five years of treatment. She was referred to the clinic with a history of recent shortness of breath and ankle swelling and was found to be in congestive cardiac failure with a blood pressure of $200 / 120 \mathrm{~mm} \mathrm{Hg}$. An electrocardiogram showed no evidence of myocardial infarction. Her blood urea concentration, previously normal, had risen to $9.5 \mathrm{mmol} / \mathrm{l}(57 \mathrm{mg} / 100 \mathrm{ml})$. Treatment was started with frusemide $80 \mathrm{mg} /$ day and spironolactone $75 \mathrm{mg} /$ day, but phenformin was not stopped. Seventeen days later she was admitted with lactic acidosis and a blood urea concentration of $50 \mathrm{mmol} / 1(300 \mathrm{mg} / 100 \mathrm{ml})$.

Comment-Although this patient's blood pressure had risen appreciably over the five years of treatment with phenformin, her blood urea concentration had been normal until heart failure developed. When diuretics were prescribed phenformin should have been stopped.

CASE 8

An obese 62-year-old woman presented with uncomplicated diabetes. She had no illnesses other than mild hypertension, for which she was taking methyldopa $250 \mathrm{mg}$ three times a day. She was treated with a reducing diet and phenformin slow-release capsules $50 \mathrm{mg}$ twice daily. Her blood urea concentration was $5.8 \mathrm{mmol} / 1(35 \mathrm{mg} / 100 \mathrm{ml})$ at the start of treatment and three months later $4.7 \mathrm{mmol} / 1(28 \mathrm{mg} / 100 \mathrm{ml})$. Six months after developing diabetes and starting phenformin she died of lactic acidosis. No obvious abnormality was found at necropsy.

Comment-This patient had the common combination of diabetes, obesity, and mild hypertension and is the type of patient for whom phenformin has been most widely prescribed. There was no biochemical or histological evidence of renal disease and screening would not have prevented her death.

\section{Discussion}

Treatment of severe phenformin-induced lactic acidosis is usually unsuccessful: two out of every three shocked patients die. $^{3-6}$ Although these results may be improved by using glucose and insulin ${ }^{12}$ or peritoneal dialysis against sodium acetate, ${ }^{13}$ it seems more relevant to consider whether this serious condition could be prevented.

The main contraindication to the use of phenformin is poor renal function, which may be mild in terms of blood urea concentration. ${ }^{9}$ In one of our patients (case 7) background retinopathy and intermittent proteinuria suggested diabetic nephropathy, although a blood urea concentration of $8.5 \mathrm{mmol} / \mathrm{l}$ $(51 \mathrm{mg} / 100 \mathrm{ml})$ was not considered high enough to warrant stopping phenformin. Although most workers have suggested that renal function should be monitored in patients on phenformin, there are no clear guidelines about how this should be done. Proteinuria is a simple clinical indication of renal disease and usually indicates at least moderate diffuse glomerular lesions. ${ }^{14}$ Proteinuria should therefore be regarded as a contraindication to the use of phenformin, irrespective of the biochemical indices of renal function. Unfortunately, the absence of proteinuria is no guarantee of normal renal function. One manufacture ${ }^{15}$ has recently recommended that serum creatinine concentration should be measured before starting phenformin and at yearly intervals thereafter and another ${ }^{16}$ that it should be measured every three months, although neither specified a level above which it is unsafe to give phenformin. Seven of our patients had normal blood urea concentrations before starting phenformin, and in five the mean was only marginally raised within three months of developing lactic acidosis. Yearly monitoring of renal function may give a false sense of security, and we suggest that the blood urea concentration should be measured before changing treatment, increasing the dose of phenformin or giving diuretics.

Any intercurrent illness associated with vomiting, especially in diabetics, may cause dehydration and impairment of renal function and is also an indication for stopping the drug. This would require specific warnings to patients and general practitioners and, even so, might be frustrated by the speed of onset of lactic acidosis.

Although acute cardiovascular diseases such as myocardial infarction or heart failure are well-known contraindications to the use of phenformin there has been only one report ${ }^{4}$ that hypertension alone is also a risk factor. Eleven of the 15 patients with lactic acidosis reported by Wise $e t a^{4}$ were hypertensive, although concurrent left ventricular failure and its treatment were probably the decisive factors in six. Five of our patients were hypertensive before starting phenformin, although blood pressure was satisfactorily controlled with methyldopa in three. 
One patient who was originally normotensive became hypertensive while taking phenformin. The results of the University Group Diabetes Programme suggest that this may be a causal relation since phenformin treatment was associated with an increase in both heart rate and blood pressure. ${ }^{17}$ Hypertension in diabetics often indicates underlying renal disease, and patients with hypertension should not be given phenformin.

Screening is unlikely to be successful when the precipitating factor may be unpredictable, such as myocardial infarction, or when lactic acidosis develops spontaneously. Two of our eight patients had no clinical or necropsy evidence of a predisposing cause other than the drug. In another series ${ }^{5} 10$ out of 18 cases of lactic acidosis were apparently spontaneous, although hypertension was not considered.

In theory, screening should prevent many cases of lactic acidosis, but we doubt whether it is practicable in busy diabetic clinics and general practices. At present there is also insufficient awareness of the condition and its relation to phenformin. It was alarming that in five patients on phenformin the possibility of lactic acidosis was not considered even when the patient presented with vomiting. The difficulties of screening were further shown in the University Group Diabetes Programme study, where, despite extremely careful supervision, three out of 204 patients developed lactic acidosis and one died. ${ }^{17}$

Many potent drugs have serious side effects, but some continue to be used because they offer a unique benefit that outweighs the risk. This is not the case with phenformin, which is a weak hypoglycaemicagent. If a biguanide is indicated metformin should be used since it appears less likely to precipitate lactic acidosis. There are so many contraindications to the use of phenformin, excluding so many diabetics, that we believe that phenformin no longer has a place in the treatment of diabetes and should be withdrawn.

We thank our colleagues for permission to report details of patients admitted under their care; Dr G Walker and the staff of the department of clinical chemistry for their help; Mrs Jane Richards for invaluable secretarial help; and Mrs Lewis and the staff of the medical library for help with references.

\section{References}

${ }^{1}$ Walker, R S, Linton, A L, Thompson, W S T, British Medical fournal, 1960, 2, 1567.

2 Oliva, P B, American fournal of Medicine, 1970, 48, 209.

${ }^{3}$ Assan, R, et al, Diabetes, 1975, 24, 791.

4 Wise, P H, et al, British Medical fournal, 1976, 1, 70.

${ }^{5}$ Fulop, M, and Hoberman, H D, Diabetes, 1976, 25, 292.

${ }^{6}$ Conlay, L A, and Loewenstein, J E, fournal of the American Medical Association, 1976, 235, 1576.

${ }^{7}$ Blumenthal, S A, and Streeten, D H P, Annals of Internal Medicine, 1976, 84, 55.

${ }^{8}$ Dobson, H L, Diabetes, 1965, 14, 811.

${ }^{9}$ Editorial, 1973, 2, 27.

10 Vinik, A I, and Jackson, W P U, South African Medical Association, 1974, $48,2021$.

${ }_{11}^{11}$ Toghill, P J, et al, British Medical fournal, 1974, 3, 545.

12 Dembo, A J, Marliss, E B, and Halperin, M L, Diabetes, 1974, 24, 28.

${ }^{13}$ Sheppard, J M, et al, Australian and New Zealand fournal of Medicine, $1972,4,389$.

${ }^{14}$ Malins, J, Clinical Diabetes Mellitus, p 163. London, Eyre and Spottiswoode, 1968 .

15 Geigy Pharmaceuticals, Diabetes, 1976, 25, April.

${ }_{16}$ Winthrop Laboratories, Surrey, Circular letter, 25 August 1976.

17 Knatterud, G L, et al, Diabetes, 1974, 24, suppl No 1, p 65.

\title{
Combined one- and two-dimensional ultrasound system for monitoring fetal breathing movements
}

\author{
J W WLADIMIROFF, C M LIGTVOET, J A SPERMON
}

British Medical fournal, 1976, 2, 975-976

\section{Summary}

A combined one- and two-dimensional ultrasonic system for monitoring respiratory movements in the human fetus has been developed. A real-time cross-sectional image of the fetal chest at the level of the fetal heart can be obtained, and a time motion recording of fetal respiratory movements can then be written on a strip-chart recorder. Combining the features of one-dimensional and two-dimensional systems produces an accurate means of investigating fetal breathing movements.

\section{Introduction}

Fetal breathing movements were first observed with simple physical equipment at the end of the last century. ${ }^{1}$ Since 1971

\footnotetext{
Department of Obstetrics and Gynaecology, Academic Hospital Dijkzigt, Erasmus University, Rotterdam, The Netherlands J W WLADIMIROFF, MD, lecturer

Department of Experimental Echocardiography, Thorax Centre, Erasmus University, Rotterdam, The Netherlands

C M LIGTVOET, IR, scientist

J A SPERMON, IR, research fellow
}

several reports ${ }^{2-7}$ have been published on monitoring breathing movements in the human fetus with ultrasonic systems. We describe here the features of a combined one- and twodimensional ultrasound system, explain the investigation technique, and present some clinical results.

\section{The system}

For the study of human fetal breathing movements a multiscan system with a 20 -element linear array transducer is used. By fast electronic switching a two-dimensional cross-sectional image is built up with a repetition rate of 50 images per second. The ultrasound image is displayed on a television screen via a line converter. The converter uses real-time processing to obtain a high line density image consisting of 157 lines per frame. A detailed description of the multiscan system and the line converter can be found elsewhere. ${ }^{8} 9$

With two thumbwheel switches each of the displayed lines can be selected and the ultrasound data from the selected line can be used for a time motion recording. This line selection technique gives the investigator vital information on the position of the selected ultrasonic beam in relation to the scanplane (fig 1). The special time gain compensation enables the operator to eliminate echoes and subsequently to differentiate between various moving structures within a certain area.

\section{Investigation technique}

The multielement transducer is positioned on the patient's abdomen and a real-time cross-sectional image of the fetal chest at the level of 